\title{
Do lugar da natureza nas teorias dedica- das à arte da harmonia tonal
}

The place of nature in theories dedicated to the art of tonal harmony

por Sérgio Paulo Ribeiro de Freitas

RESUMO

Aborda-se aqui a versada temática dos usos e sentidos do termo natureza focando algumas de suas repercussões no campo da cultura teórica musical moderna e contemporânea. Tomando como ponto de partida o entorno de Jean-Philippe Rameau (1683-1764), delineia-se um conjunto de referências sobre o como, o quando, o onde e o porquê algo como a arte da tonalidade harmônica, criada pela intelecção e pelo trabalho das mãos humanas, agregou o tradicional valor de coisa derivada, pertencente, gerada ou produzida pela natureza. Contrapondo observações de diversos comentaristas aos conceitos e conotações elencadas no artigo "Nature as Aesthetic Norm" publicado em 1927 pelo historiador estadunidense Arthur Oncken Lovejoy (1873-1962), o presente texto revê um conjunto de noções e subentendidos consagrados que, de maneira consideravelmente emaranhada, ora mais ou ora menos, nos fazem confiar ou desconfiar do preceito de que a bela harmonia sela acordo com as leis da bela natureza.

Palavras chave: Natureza; Estética musical; Teoria Musical; Harmonia tonal.

\section{ABSTRACT}

We discuss here the theme of the uses and meanings of the term nature focusing some of its repercussions in the field of contemporary and modern music-theoretical culture. Taking as starting point the environment of Jean-Philippe Rameau, this study outlines a set of references on how, when, where, and why something like the art of harmonic tonality, created by intellection and by the work of human hands, added the traditional value of something derived, owned, generated or produced by nature. Contrasting observations of several commentators to the concepts and connotations listed in the article "Nature the Aesthetic Norm," published in 1927 by the American historian Arthur Oncken Lovejoy (1873-1962), this article reviews a set of notions and implications that, so considerably tangled, sometimes more or sometimes less, make us trust or distrust the precept that the beautiful harmony agrees with the laws of the beautiful nature.

Keywords: Nature; Musical Aesthetics; Music Theory; Tonal Harmony 


\section{Do lugar da natureza nas teorias dedicadas à arte da harmonia tonal}

À natureza pertencem aquelas coisas que tem em si
mesmas o princípio de movimento e de repouso Aristóteles

Com o título "escalas naturais" um estudante de música no ensino superior criou um tópico em uma rede social propondo o debate acerca do uso do termo "natural" no vocabulário teórico da disciplina harmonia. Tal proposta dá ensejo para um exercício de dimensionamento da questão e, ao mesmo tempo, oportuniza um diálogo com aqueles que, como este estudante, ainda se preocupam com esse tipo de coisa. Para retomar 0 assunto, e ao mesmo tempo sinalizar a longevidade da relação entre ideias de harmonia e natureza, podemos reler uma passagem na qual o teórico musical grego, Cláudio Ptolomeu (c. 90-168) - em seu tratado "La Harmónica", considerado uma "síntese de todo o desenvolvimento teórico da ciência musical na Antiguidade Helênica" (REYES, 2002, p. x) - procura responder a pergunta "Qual é o propósito do estudioso da harmonia?"

0 propósito do estudioso da harmonia seria preservar em todo momento as hipóteses racionais do cânon [0 monocórdio]. Pois em todas as coisas é próprio do investigador teórico e entendido mostrar que os trabalhos da natureza estão modelados com uma certa razão, uma causa ordenada e em absoluto de modo ao acaso, e que nada se leva a cabo por meio deste modo casual ou fortuito, sobretudo nas mais belas disposições [composições], aquelas que alcançam os mais racionais sentidos, para a vista e para o ouvido (PTOLOMEU in: REYES, 2002, p. 143).

Para situar a questão no mundo musical moderno, já harmônico e tonal, uma das referências é o versado programa do teórico e compositor francês Jean-Philippe Rameau (1683-1764). Como se sabe, na história da teoria da harmonia os esforços de Rameau representam um ponto de confluência de várias heranças culturais, artísticas, teórico musicais, práticas e científicas e, ao mesmo tempo, são um marco fundador das teses que defendem que, também na bela ciência da tonalidade harmônica, as regras devem se fundamentar em princípios naturais. Tomemos algo do seu apreço pelo "princípio único" conhecido na esfera musical do lluminismo francês como "corps sonore". 0 gerador natural a ser imitado que, grosso modo, corresponde àquilo que, atualmente e no senso comum, chamamos de série harmônica. ${ }^{2}$ Em seu "Démonstration du principe de I'harmonie..." publicado 1750, Rameau sintetiza o ideal da noção:

Quantos princípios emanados de um só! É necessário recordá-los, senhores? Só da ressonância do corpo sonoro acabam de ver nascer a harmonia, o baixo fundamental, [...] o gênero maior e o menor, quase toda a melodia, o "double emploi", fonte fecunda de uma das mais belas variedades, os repousos, ou cadências, a ligação que, sozinha, pode manter as vozes em uma infinidade de relações e sucessões, e inclusive a necessidade de um temperamento [...] sem falar no modo menor, nem da dissonância, sempre emanadas do mesmo princípio [...]. Por outro lado, com a harmonia nascem as proporções, e com a melodia as progressões, de

$1 \quad$ Citado em Tatarkiewicz (2002, p. 327).

2 XXXX. Sobre a imitação dessa natureza na esfera do luteranismo, cf. Harnoncourt (1990, p.78-

79) e Lucas (2009). 


\title{
Do lugar da natureza nas teorias dedicadas à arte da harmonia tonal
}

\begin{abstract}
sorte que estes primeiros princípios matemáticos, encontram eles mesmos aqui seu princípio físico na natureza. Assim, essa ordem constante que temos reconhecido como consequência de uma infinidade de operações e combinações, precede toda combinação e toda operação humana, e se apresenta, desde a primeira ressonância do corpo sonoro, tal como a natureza the exige: assim, o que não é mais que indicação se converte em princípio, e o órgão [o ouvido], sem o auxílio do espírito, aprova aqui aquilo que o espírito havia descoberto sem a intromissão do órgão; e isto deve ser, ao meu entender, um descobrimento agradável aos sábios, que se conduzem pelas luzes metafísicas, um fenômeno em que a natureza justifica e funda plenamente os princípios abstratos (RAMEAU, 1750, p. 59-62). ${ }^{3}$
\end{abstract}

A crença neste "naturalismo racional" (TATARKIEWICZ, 2002, p. 331), compartilhada por vários personagens da época, alcança, conforme Rowell (2005, p. 106-108), a dimensão de que, para Rameau, a harmonia se modela inconscientemente a partir de certas naturezas que pertencem ao ser humano desde antes de seu nascimento. Conceitos inatos como nossa propensão para perceber como estável a sonoridade de uma tríade simples com sua fundamental no baixo, ou nossa capacidade congênita de reagir naturalmente à oposição psicológica básica dos modos maior e menor ou aos fenômenos rítmicos simples como a pulsação, a acentuação e a métrica. Dadas essas naturezas, a mente racionalmente deduz ou subentende o conjunto de leis da tonalidade e confirma sua existência quando se expõe aos seus efeitos musicais.

Validando direta ou indiretamente a "utopia dos enciclopedistas, segundo a qual tudo o que está ligado a natureza é bom" (CANDÉ, 1989, p. 19), tais teses repercutem até os dias de hoje. Sustentam aqueles argumentos que, ambicionando explicar o funcionamento global da harmonia tonal, já foram categorizados como "princípios transcendentes" (NATTIEZ, 1984, p. 257). Princípios que nos parecem verdadeiros, pois, dentre outros fatores, de Zarlino a Rameau, de Kirnberger a Sechter, de Hauptmann a Riemann, de Schenker a Hindemith, foram muitos os harmonologistas que, com diferentes ênfases, se dispuseram a defender o natural em nossa arte.

A ideia de uma música dada pela natureza e não feita pelo homem, foi tão poderosa no século XIX que a teoria musical nunca abandonou a ideia segundo a qual a harmonia tonal da modernidade estivesse fundada no som natural, apesar de algumas objeções [...] tão graves, que se exigia uma forte resistência interior para não se deixar convencer por elas (DAHLHAUS, 1999, p. 145).

Tais princípios estão no dia a dia da disciplina, assim, para economizar algo mais do que mil palavras, vale rever uma figura emblemática, já comentada em XXXX, Gollin (2000, p. 145-151) e Lester (1996, p. 229-230). Trata-se da metafórica “Arbre Genealogique de I'harmonie" estampada aproximadamente em 1767 pelo músico francês François-Guillaume Vial (c.1730-?). Para Lester, nenhuma inspeção ao pensamento harmônico do século XVIII será completa sem essa persuasiva ilustração pedagógica que, como se vê na Fig. 1, reúne vários fundamentos. No sentido horizontal a árvore naturaliza 3 Tradução nossa. Sobre o duplo emprego (double emploi), cf. Christensen (1993, p. 193-197), Dahlhaus (1990, p. 24-25), XXXX, Harrison (1994, p. 93-94), Lester (1996, p. 133-135), Rousseau (2007, p. 188-190) e Wason (1995, p. 38, 63, 155-156). Sobre as teses de Rameau e suas repercussões, cf. Christensen (1993), Fubini (2002, p. 57-91), Lester (2006), Moreno (2004) e Shirlaw (1969). 


\section{Do lugar da natureza nas teorias dedicadas à arte da harmonia tonal}

vizinhanças de quinta elencando, no interior de cada esfera, ou fruto, os três acordes ditos principais ou básicos (I, IV6 e V7) de cada tonalidade. As fundamentais são grafadas com notas pretas evidenciando relações de quarta e quinta no tom maior e em seu respectivo relativo menor. Além da sugestão de que "a força inerente ao parentesco" gera a patriarcal "família tonal" (HINDEMITH, 1962, p. 114-115), e de que "as harmonias assim como os descendentes" são "criações da natureza" (SCHENKER, 1990, p. 70), observa-se, ao pé da árvore, a voga da alegoria magnética, a força natural universalmente capaz de determinar rumos e progressões: a bússola por quinta à esquerda e a por terceira à direita. Em suma, acordes gerados em árvore, combinados segundo a inexorável atração exercida por um centro de gravidade, sustentam a naturalidade da bela harmonia.

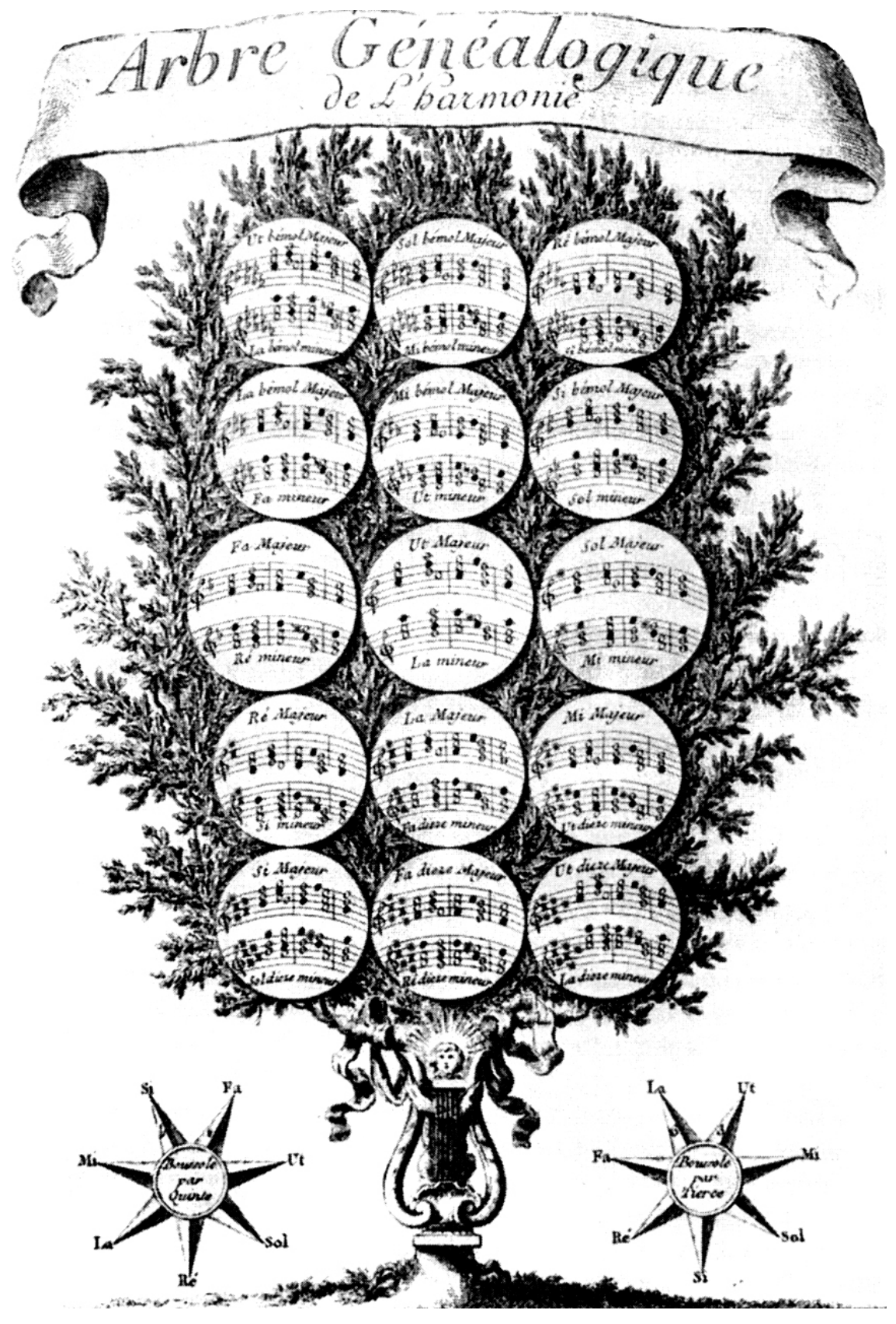

Fig. 1 - Acordes e progressões naturalizadas na "Arbre Genealogique de I'harmonie" de Vial, c.1767 


\title{
Do lugar da natureza nas teorias dedicadas à arte da harmonia tonal
}

Entretanto e gradativamente, como nota Dahlhaus no trecho supracitado, enquanto a harmonia natural se consolida como sistema mais e mais verossímil, objeções foram se insurgindo contra essa "física muito estranha", como ironiza Rousseau (1978, p. 198) acusando os inconvincentes experimentos e deduções que sustentam as teses de Rameau.

\begin{abstract}
Um som traz consigo todos os seus sons harmônicos concomitantes, nas relações de força e de intervalos que devem ter entre si para conseguir a mais perfeita harmonia desse mesmo som. Acrescentai ainda uma terça e uma quinta ou alguma outra consonância; não a estareis acrescentando, estareis redobrando-as; conservais a relação de intervalo, mas alterais a força. Ao reforçar uma consonância e não as outras, estareis rompendo a proporção; ao desejar fazer melhor do que a natureza, fazeis pior. Vossos ouvidos e vosso gosto são corrompidos por uma arte mal compreendida. Naturalmente, não há outra harmonia além do uníssono (ROUSSEAU, 2008, p. 154).
\end{abstract}

Um dos muitos registros que, na passagem do mundo moderno para o contemporâneo, documentam a imperativa necessidade de uma redefinição da noção de natureza, encontra-se na correspondência trocada entre o compositor alemão Carl Friedrich Zelter (1758-1832) e o poeta Johann Wolfgang von Goethe (1749-1832). De 1808 ao fim de suas vidas, Zelter e Goethe discutiram um famoso calcanhar-de-aquiles da teoria musical: 0 fundamento natural da terça menor, e logo, também do acorde, escala e modo menor. Goethe sublinha o apreço "universal" pela sonoridade da "terça menor" e por "tudo o que dela surge", apesar da "liga de nossos teóricos da música" não a admitirem como um donum naturae. Ao que o zeloso Zelter reitera:

Nossa escala tonal, hoje diatônica (natural), surge da divisão de uma corda. Dividese a corda ao meio, obtém-se a oitava. Divide-se a corda em 3 partes tem-se a quinta justa; divide-se a corda em 5 partes e surge a terça maior. Pode-se dividir a corda em quantas partes se queira que jamais surgirá uma terça menor [...]. Isso significa que a terça menor não é nenhum donum imediato da natureza e sim uma obra da nossa arte. [...] Nossa teoria tornou-se um sistema que precisa ser aprendido e ensinado. Não há dúvida de que, com isso, ocorreu em certa medida uma violentação da natureza. Trata-se, porém, de uma tessitura engenhosa de modificações que se podem observar, quase que sem nenhum espanto, já que os músicos guardam a crença de que o que não se pode edificar com esse sistema não é para ser edificado (ZELTER apud SCHUBACK, 1999, p. 33-34 e 39).

Em duro golpe contra as razões monocordistas, os argumentos de Coethe são "contagiantes", como reconhece o próprio Zelter. Eis alguns fragmentos de suas cartas:

Oponho-me, na verdade, a que somente a escala diatônica seja natural. [...] Tratase, sem dúvida, de um belo experimento o fato de a divisão das cordas em partes determinadas fazer surgir sonoridades harmônicas para o ouvido e que ainda estruturam uma certa escala tonal. Mas o que não acontece desse modo não 


\title{
Do lugar da natureza nas teorias dedicadas à arte da harmonia tonal
}

\begin{abstract}
poderia ser compreendido de outra maneira? [...] Seria exigir demais que um único experimento possa gerar tudo. [...] Uma corda de tripa ou de metal não está tão acima dos seres humanos para que a natureza tivesse concedido exclusivamente a elas a suas harmonias. Como o homem tem mais valor e como a natureza cedeu ao homem a terça menor para que ele exprimisse com o mais íntimo conforto a nostalgia inominável, o homem pertence igualmente à natureza, sendo aquele que apreende em si mesmo as relações mais suaves do conjunto das manifestações elementares, sabendo regrá-las e modificá-las (GOETHE apud SCHUBACK, 1999, p. 35-42).
\end{abstract}

Goethe parece contagiado pelo entusiasmo pré-romântico de um Joseph Berglinger, o herói imaginário do ensaio, datado de 1797, de Wilhelm Heinrich Wackenroder (17731798). Diante da magia que a música exerce sobre o espírito, Berglinger revolta-se contra a pequenez da razão mecânica monocordista: "Olho e não encontro nada mais do que um miserável tecido de proporções numéricas representadas de modo manifesto sobre a madeira talhada, em uma armação com cordas de tripa e arame" (WACKENRODER apud DAHLHAUS, 1999, p. 146).

Outro influente pensador alemão que, nesses mesmos anos, ajudou a minar a "tendência classicista" de que "o que não se pode edificar" a partir das alíquotas do monocórdio "não é para ser edificado" foi Arthur Schopenhauer (1788-1860). Apoiando-se em cálculos de Ernst Florens Chladni (1756-1827), o cientista alemão considerado então "o pai da acústica moderna", Schopenhauer elabora mais uma de suas analogias. Aqui a comparação se estabelece entre as contradições do sistema musical, supostamente ancorado em um princípio sólido, mas incapaz da perfeição, e as contradições que se instalam no íntimo do próprio ser humano.

\footnotetext{
Um sistema perfeito puramente harmônico dos tons não é apenas física, mas também aritmeticamente impossível. Os próprios números, pelos quais os tons permitem expressão, ostentam irracionalidades insolúveis; não é possível calcular uma escala em cujo interior toda quinta se relaciona com o som fundamental na proporção de 2 para 3, toda terça maior como 4 para 5, toda terça menor como 5 para 6 etc. Pois se os tons estão corretos em relação ao tom fundamental, não o são entre si, na medida em que, p.ex., a quinta deveria ser a terça menor da terça etc. [...] Por isto, uma música perfeitamente correta não pode sequer ser pensada, quanto mais executada; e por isto toda música possível [como todo indivíduo possível] se desvia da pureza perfeita (SCHOPENHAUER, 1974, p. 87). ${ }^{4}$
}

Aos poucos, tais discursos de oposição ganharam lugar também entre os músicos pensadores da harmonia. Nattiez (1984, p. 256) reconhece no "Traité complet de la théorie et de la pratique de l'harmonie", concebido desde 1815 e publicado em 1844 pelo compositor e musicólogo belga François-Joseph Fétis (1784-1871), o "imenso mérito de recusar a basear a harmonia numa lei natural [...] o que era absolutamente revolucionário para a época". Em 1863, o fisiologista e físico alemão Hermann von Helmholtz (18211894), em seu influente "Tratado das sensações sonoras como fundamento fisiológico para a teoria musical", chega à novas conclusões acerca da Naturklangtheorie:

$4 \quad X X X X$ 


\section{Do lugar da natureza nas teorias dedicadas à arte da harmonia tonal}

O sistema de Escalas e Modos e Tecidos Harmônicos não descansa somente em leis naturais inalteráveis, mas também é, ao menos em parte, o resultado de princípios estéticos, os quais já se transformaram e irão ainda continuar se transformando com o progressivo desenvolvimento da humanidade (HELMHOLTZ, 1954, p. 235).

Em 1911, surge o "Harmonielehre" de Arnold Schoenberg (1874-1951) e, com este e outros escritos do autor, a tese da "rejeição da tonalidade como uma lei natural" (DUDEQUE, 2005, p. 37-38) ganha uma das mais incisivas defesas contemporâneas. Sublinhando a "diferenciação entre o material dado pela natureza e a sua intelectualização pelo artista, ou em outras palavras, a diferença entre natureza e arte" (DUDEQUE, 1997, p. 24), Schoenberg defendeu argumentos que se tornaram referências no enfrentamento das teses que apregoam uma suposta naturalidade da tonalidade, contribuindo para a formulação de uma espécie de contra entendimento acerca da nossa disciplina: "a tonalidade é artificial e derivada de um processo histórico" (DUDEQUE, 1997, p. 24).5

\section{Usos, sentidos e conotações de uma palavra sem dono: natureza}

Qualquer história completa dos usos de natureza, seria a história de grande parte do pensamento humano.

Raymond Williams

Numa narrativa da história da música ocidental, Grout e Palisca (1994, p. 480) sublinham que natureza foi a grande palavra-chave do lluminismo, um termo que recebeu os mais variados sentidos, muitas vezes vagos e até opostos. Com o auxílio de exames realizados em diferentes épocas, em diversas áreas e por distintos autores, ${ }^{6}$ faz-se notório que, também na história das ciências, da linguagem, da ética, do belo (da estética), da religião, das relações sociais e dos juízos filosóficos, a polissêmica palavra está presente nas altercações entre o natural e o artificial, a natureza e a cultura, a natureza e a arte e a natureza e a história. Para Micheli (1990), na acepção mais geral - que parece se adequar, ao menos em parte, ao sentido que Rameau dá ao termo - natureza indica o conjunto das coisas que existem referindo-se não tanto a sua configuração determinada e objetiva, mas sim aos seus princípios constitutivos essenciais.

Conforme Williams (2007), natureza deriva do latim natura, a partir da raiz nasci (nascer), do qual derivam também nação, nativo, inato etc., que corresponde ao verbo grego physein (ser gerado), que consigo traz a noção de que todas as coisas quando nascem realizam-se sempre segundo uma característica própria inseparavelmente sua.? Para

$5 \quad$ Cf. Lévi-Strauss (1991, p. 29-30).

$6 \quad$ Autores como: Abbagnano (1982), Batteux (2009), Clark e Rehding (2001), Collingwood (2006), Crawford (2008), Kawana (2006), Leach (1985), Lenoble (1990), Micheli (1990), Montgomery (1992), Shirlaw (1969), Tatarkiewicz (2002), Tomás (2011) e Zilles (2002).

7 Micheli (1990) observa que Lenoble, em sua "História da ideia de natureza", chamou atenção para o tema do nascimento, destacando que natureza estende para todas as coisas a explicação vitalista da geração dos indivíduos, de onde se deriva a visão da natureza como um imenso ser vivo (Mãe Natureza). Natureza então designa os órgãos genitais (que se destinam à geração), principalmente os 


\section{Do lugar da natureza nas teorias dedicadas à arte da harmonia tonal}

Williams, natureza talvez seja a palavra mais complexa da língua (inglesa), com muitos significados precisos variáveis e muitas vezes inversos. Williams distingue três amplos campos a partir dos quais se desenvolvem algumas variações poderosas. Natureza como: (i) a qualidade e o caráter essenciais de algo; (ii) a força inerente que dirige 0 mundo e/ou os seres humanos; (iii) o próprio mundo material.

Natureza é dessas palavras que, como as palavras cultura e tradição, surgem como descrições de uma qualidade ou de um processo, que a princípio se definem por referência específica e que, mais tarde, tornam-se substantivos independentes e abstratos. No campo da estética musical, os sentidos de natureza variam de um extremo a outro:

Durante o século XVII o termo natureza se emprega como sinônimo de razão e de verdade $^{8}[\ldots]$. No entanto, durante a segunda metade do século XVIII, encontramos o termo natureza sendo empregado, quase paradoxalmente, como símbolo de sentimento, espontaneidade e expressividade (FUBINI, 1994, p. 178).

A íntima proximidade da harmonia com esta "natureza dividida" (KAWANA, 2006) está documentada na pauta da Querele dês Bouffons: "Rameau defende a música como imitação da natureza por meio de seus fundamentos físico-matemáticos" enquanto que, para Rousseau, "natureza é sinônimo de paixão, sentimento [...] e é clara e polemicamente contraposta à razão" (FUBINI apud VIDEIRA, 2006, p. 39). Então, como formula Salazar (1984, p. 35), temos natureza como algo "fora de nós" ou como algo "dentro de nós". Fora de nós, a natureza é, para os artistas, paisagem e, para os naturalistas, ciência. Dentro de nós, se converterá em psicologia, e aí natureza e humanidade se confundem. ${ }^{9}$

Assim, mesmo na esfera culta ou estritamente formal, parece árdua a tarefa de decifração dos vários sentidos que a palavra natureza pode denotar. Todavia, considerando que natureza "passou para o patrimônio das crenças comuns de nosso mundo e por isso aparece, sem se fazer notar, nas mais elaboradas concepções" (ABBAGNAN0, 1982, p. 670), para as finalidades dos estudos musicais, é significativo considerar também 0 registro coloquial, os usos não rigorosos e emaranhados que o termo natureza apresenta a cada instante.

femininos. Como a palavra nação tem a mesma origem, e também significa nascimento (de onde Filhos da Pátria), surge o paralelismo entre natio, unidade de parentesco, e natureza, unidade dos seres vivos.

8 Conforme Cassirer (1997, p. 374), nessa doutrina clássica, “pode-se aceitar 'natureza' como sinônimo de 'razão'; tudo vem da natureza, tudo lhe pertence, do que não é produto fugaz do instante, o fruto do humor ou do artifício, mas funda-se, pelo contrário, nas leis de bronze da ordem eterna. Esse fundamento é o mesmo para aquilo a que chamamos 'beleza' e para o que chamamos 'verdade'”. $9 \quad$ As expressões "fora" e "dentro de nós" se tornaram códigos no mundo da música culta para indicar possíveis associações entre música e filosofia, ou mais especificamente, entre Beethoven e Kant. Lockwood (2004, p. 29) registra esse tipo de associação: somos "sujeitos ativos moralmente livres e independentes da ordem causal da natureza", este epigrama kantiano resume a missão de Beethoven, que o leva a lutar por meio de sua arte "para alcançar o mundo transcendental da ordem mais elevada das coisas". Em 1820, Beethoven escreve: "Existem duas coisas que elevam o homem acima de si mesmo e levam ao eterno e sempre na direção ascendente [e então cita Kant]: a lei moral dentro de nós e o céu estrelado acima de nós. Kant !!!" (LOCKWOOD, 2004, p. 446). 


\section{Uma leitura emaranhada das acepções de "natureza" consideradas por Lovejoy}

0 conceito e a palavra 'natureza' é um verdadeiro pau para toda obra.

Friedrich Nicolai ${ }^{10}$

Vários comentaristas referenciam o esforço do historiador estadunidense Arthur Oncken Lovejoy (1873-1962) que, no artigo "Nature as Aesthetic Norm" de 1927, reúne uma generosa coleção dos usos e sentidos que personagens europeus dos séculos XVII ao XIX associaram aos termos natureza e natural. Dentre os notáveis que aparecem no elenco de Lovejoy estão nomes como Shakespeare, Molière, Batteux, Shaftesburry, D’Alembert, Diderot, André, Rousseau, Herder, Friedrich Schlegel e Schiller. A síntese de Lovejoy é difícil de ser novamente abreviada, nela, de acordo com o contexto, o termo natureza pode assumir algum ou combinar vários dos sentidos relembrados a seguir. Esta reunião de acepções pode servir como um prelúdio à inextricável imersão conceitual que se desencadeia quando, no âmbito das práticas teóricas da harmonia tonal, recorremos propositalmente ou desavisadamente aos termos: natureza, natural, naturalidade, naturalmente etc. Vejamos:

Conforme Lovejoy (1965, p. 69-77), natureza é o objeto a ser imitado, no sentido de realidade empírica a ser reproduzida ou representada na arte. É o oposto de humano, ou de seu trabalho ou arte, é a parte da realidade que não foi transformada ou corrompida pelas mãos do homem. Natureza é a natureza humana, o comportamento humano possível ou usual. É a expressão das paixões, temperamentos e afeições. Pode ser a natureza das coisas, um sistema de verdades inevitáveis e auto-evidentes. Natural corresponde a uma ideia de natureza em geral, de ordem cósmica como um todo, ou essa ordem parcialmente representada manifestando-se em um exemplar, como no caso da lei da gravitação e sua representação idealizada no sistema tonal, que desse modo é percebido como natural ou como parte da natureza. ${ }^{11}$

Natural agrega atributos variados: uniformidade, simplicidade, economia, plenitude, regularidade (fator geometrizante), irregularidade, caráter "selvagem", abundância, variedade de conteúdo e fecundidade insaciável. E como consequência, a justaposição de características muito contrastantes. Natureza pode expressar as interconexões reais entre fatos, as relações de causa e efeito que (naturalmente) ocorrem na experiência humana. Neste sentido, Abbagnano (1982, p. 671) lembra uma formulação útil para a abordagem funcional da harmonia: para o filósofo inglês Alfred Whitehead (1861-

10 Lovejoy inicia seu artigo com este epigrama atribuído ao escritor alemão Christoph Friedrich Nicolai (1733-1811). Cf. Crawford (2008, p. 388).

11 Conforme Abbagnano (1982, p. 671) para Galilei a natureza é a ordem do universo, "uma ordem que é única e que nem nunca foi nem será diferente". Para Newton "A natureza é bastante consonante e de acordo consigo própria". Para o filósofo anglo-irlandês Robert Boyle (1627-1691), a natureza "não deve ser considerada como um agente distinto e separado, mas como uma regra, ou antes, um sistema de regras [...]". Para Kant a natureza (em sentido empírico) é a conexão dos fenômenos, por sua existência "segundo regras necessárias ou leis". Assim, a natureza em Rameau - o "Newton da harmonia" (CHRISTENSEN, 1993, p. 7) - está em sintonia com toda uma longa história. XXXX. 


\section{Do lugar da natureza nas teorias dedicadas à arte da harmonia tonal}

1947), em seu The Concept of Nature de 1920, natureza é "um complexo de entes em relação" onde a ênfase é posta sobre relação, o que atribui à filosofia natural a tarefa de "estudar como se ligam os vários elementos da natureza". ${ }^{12}$

Natureza significa essência eterna e puramente inteligível, ou a ideia platônica das coisas sensiveis, imperfeitamente realizadas na realidade empírica, portanto, um tipo formal idealizado, la belle nature, i.e., a natureza "excluída de seus defeitos" (LUCAS, 2009, p. 30). ${ }^{13} \mathrm{E}$ pode significar a diversificação progressiva de tipos básicos no tempo, uma sorte de evolução contínua ligada à concepção de organicismo. ${ }^{14}$ Natureza corresponde aos princípios intuitivamente conhecidos, ou aos padrões de gosto consagrados, tacitamente percebidos como análogos às leis da natureza, e através dos quais, objetivamente e essencialmente, isto é, por natureza, a beleza é reconhecida. Com isso, Batteux (2009, p. 59) defende que "o gosto é, pois, como o gênio, uma faculdade natural que apenas pode ter como objeto legítimo a própria natureza ou o que a ela se assemelha".

Natural equivale a um tipo genérico que exclui diferenças individuais. Ou um caso comum: -é natural porque ocorre sempre. Natural é o que é familiar e íntimo para cada indivíduo ou para cada grupo, variando com a época, etnia, origem e tradição cultural. Natural é racialismo e nacionalismo na arte. É nativismo, é ter raízes e, geralmente, ter aversão a aculturação e ao estrangeirismo. Pode ter sentido de naturalidade, atributo essencial do artista, nesse caso naturalidade agrega significado de liberdade frente aos valores de convenção, regras, tradições e hábitos. Natural é a espontaneidade, o mais natural sentimento na natureza humana. Conforme Abbagnano (1982, p. 669), natural é um princípio de vida e de movimento de todas as coisas, daí expressões como: "deixar agir a natureza", "abandonar-se à natureza", "seguir a natureza" etc.

Natural pode ter sentido de autoexpressão sem autoconsciência e assim qualificar a manifestação livre de premeditação, de ensaio ou planejamento. Indica ausência de análises e artificialismos e contrasta-se com aquilo que foi naturalizado. Naturalidade pode se referir ao comportamento do público do artista, portanto uma qualificação do apelo expressivo ou da validade estética da sua obra. Naturalidade agrega significados de universal e imutável, de sentimento e sensibilidade, de aquilo que sempre foi conhecido, que todo mundo pode entender e desfrutar imediatamente e, geralmente, está conectado com a suposição de que o apreciado universalmente é também o verdadeiramente belo.

A questão de saber se a arte está ou não de acordo com a natureza fundamenta-se em um ou outro dos seguintes sentidos: natural é o realismo literal, a fidelidade de reprodução ou a imitação de eventos, geralmente conotando algo convincente e possível. Natural é então o verossimilhante, é o que parece verdadeiro ou é provável. 0 natural sustenta que a obra de arte deve ser julgada pelos efeitos que causa naturalmente no observador, no leitor, no ouvinte etc. Implica restrição de aparatos altamente sofisticados e sobrenaturais, ou do emprego de figuras mitológicas e daquelas artes ou gêneros que descrevem tipos exageradamente ideais. Natural é a descrição de tipos comuns, implica adesão aos padrões de beleza objetiva, ao planejamento estrutural de fácil entendimento. Naturais são os valores comumente identificados com simplicidade, com

\begin{tabular}{ll}
\hline 12 & XXXX \\
13 & XXXX \\
14 & Cf. Clark e Rehding (2001), XXXX, Montgomery (1992) e Rowell (2005, p. 120).
\end{tabular}




\section{Do lugar da natureza nas teorias dedicadas à arte da harmonia tonal}

poucos ornamentos e que evitam armações intrincadas. Aqui podem surgir sugestões de simetria, equilíbrio, definição e regularidade da forma. Mas também é natural a imperfeição, a ausência de simetria e das formas recorrentes ou fixas.

Natural pode se associar ao homem primitivo ou arte primitiva. Ter valor de naïf, de rusticidade ou representar a vida e as afeições das pessoas e sociedades não sofisticadas. Pode evocar a desconsideração de regras e dos valores precedentes por parte de um artista desvinculado de escolas convencionais e geralmente, não necessariamente, identificado com o desconhecimento e a auto-aprendizagem. Mas, natural é também a imitação de modelos estabelecidos que, em conformidade com a natureza, têm aceitação longa e continuada. Natural é a expressão do que é mais distintivo e familiar em um artista para o seu público imediato. É a expressão moderna, humana e laica que, ancorada nas inspirações da razão e do coração, distingue-se da manifestação regulada pelos preceitos metafísicos cristãos. É a manifestação artística de cada período do seu próprio espírito de época (zeitgeist), é a característica genérica de um período específico. Natural significa a completude de representação da vida humana e dos aspectos do mundo sensível, a expressão dessa enorme complexidade, diversidade, imensidão e riqueza. 0 natural tende a valorização do conteúdo em detrimento da forma na arte, tende ao individual e à mistura dos gêneros. Significa a diversificação gradual e a expansão dos conteúdos e formas da arte. É evolução estética contínua e o culto da originalidade e da novidade. É o sentimento de natureza (Naturgefuhl) herdado dos românticos, a expressão das emoções derivada da contemplação do mundo externo sensível ao homem, especialmente quando concebida como uma fonte de ensinamento moral ou como uma manifestação de, ou meios de contato com, alguma presença espiritual penetrante. Natural é a função do artista concebida como expressão de sua reação subjetiva, não uma simples imitação do mundo externo, senão a sua interpretação do significado íntimo desse mundo exterior.

Por sua herança mista, eclesial, aristocrata e burguesa, o vocabulário erudito da tonalidade harmônica emprega o tópico natural também como uma espécie de subterfúgio que, de maneira explícita ou não, dissimula a carga moral, ética, social, religiosa e política de termos indisfarçavelmente autoritários. ${ }^{15}$ São várias as metáforas pedagógicas que naturalizam os dogmas e hierarquias dos regimes de poder absoluto: Natural é o acorde, aquilo que está de acordo. Natural é toda consonância, que por aceitação sintônica dirime a distensão. Natural é o intervalo justo que agrega valor de julgamento preciso, irrepreensível, reto e íntegro e que está em conformidade com a razão. Natural é o perfeito, pois possui as melhores qualidades e não contém erros em relação às exigências das leis à que se submete. É a subjugação do menor (modo noturnal, opaco e entristecido) pelo maior (poderoso, brilhante e feliz). É a escala temperada e afinada que revela o polimento e a racionalização necessária para a agradável civilidade. É começar e terminar no tom, ação que agrega valor moral de coerência e assegura a não adoção de incertezas cujas consequências são nitidamente indesejáveis. Natural é a nota real que, como um rei ou rainha, controla as relações com as notas auxiliares, que por seu valor secundário, servem posicionadas na parte

15 Como se sabe, nos tempos em que personagens como Rameau trabalham na institucionalização das modernas leis, regras e proibições da harmonia vigora, na França e em outras cortes, o regime do absolutismo. Com isso lidamos com termos que, marcados pelo despotismo, pela tirania e pela arbitrariedade daqueles anos, continuam incomodando a teoria musical até hoje. 


\title{
Do lugar da natureza nas teorias dedicadas à arte da harmonia tonal
}

fraca do compasso, ou, caso contrário, devem ser claramente purificadas por redenção e conduzidas até a nota realmente pertencente ao acorde. Natural é a nota principal - a mais considerada, a mais importante, a essencial etc. -, que por isso pode saltar e sustentar a melodia e harmonia. Como um príncipe ou princesa, a nota principal naturalmente recebe ornamento que, por sua vez, não será natural se aparecer a todo momento e, recomenda-se, não deve deixar de ser devidamente preparado e resolvido. Naturais são as notas e acordes que, sem misturas, sem acidentes ou alterações, pertencem aos domínios defendidos pela armadura, o conjunto de armas que, na clave, protege os domínios do tom.

\section{Considerações finais}

\begin{abstract}
A construção de escalas e do tecido harmônico é produto da imaginação artística, e não está sujeita de forma nenhuma a formação natural ou a função natural de nosso ouvido, como até agora vem sendo amplamente afirmado.
\end{abstract}

Hermann von Helmholtz ${ }^{16}$

Desta leitura depreende-se que, nas práticas teóricas da harmonia, dependendo da situação e propósito, a palavra natural pode rejeitar ou privilegiar traços separados ou combinados em um amplo campo de sentidos. Como um qualificador previamente maturado, o termo natureza impõe uma ideia de ordem e necessidade à teoria musical, posto que aquilo que é dado como natural pode atuar como "fonte de legitimação para as regras que são propostas, como uma autoridade que gera leis supostamente incontestáveis e como um recurso de conhecimento e valor aparentemente inatingível pelas mudanças culturais e históricas" (CLARK e REHDING, 2001, p. 2).

A natureza apossada por um discurso desempenha funções persuasivas. Com este termo a retórica teórica agrega créditos de racionalidade, respeitabilidade, notoriedade, predileção e verdade. Esta eloquência persuasiva produz também o resultado oposto ao esperado. Exagerado, o convencimento parece falso, como uma espécie de propaganda enganosa tais rótulos - escala natural, acorde natural, harmonia natural - soam como cerceio ou impostura daqueles que, idealizando a natureza corrigida, procuram enganar a natureza. Aqui convém parafrasear Moisés (1988, p. 161): a harmonia tonal não é natural. Deseja-se natural, finge-se natural sabendo que, por definição, é antinatural. Ainda assim pretende-se natural, à imagem e semelhança da natureza, com isso, 0 natural nela mostra-se fingido.

Tal amálgama, embora muito resumido aqui, mostra-se suficiente para embasar a conclusiva de que, o termo natureza e suas conotações estão em uso no senso comum, são moeda corrente nas disputas formais e informais acerca das questões musicais. Com isso, o centro da problemática pode ser ligeiramente deslocado. Ao longevo dilema que perpassa as eras da música ocidental - a harmonia é ou não natural? Está ou não baseada na natureza? Imita ou não a natureza? - podemos contrapor outra questão de fundo: dada a constatação de que o termo está posto, como compreender qual é 16 Helmholtz (1954, p. 365). 


\section{Do lugar da natureza nas teorias dedicadas à arte da harmonia tonal}

o campo de sentidos com o qual estamos lidando a cada situação em que a palavra natural é evocada? Desde muito antes de Rameau até os dias de hoje, a entremeação de noções de harmonia e natureza gera rodeios, evasivas, verbalismos, psitacismos e sofismas sem fim. Tais termos possuem uma incrivel capacidade de se adaptar, de se transformar e de ganhar significado objetivo e crível a partir de argumentações bem definidas e convincentes, conforme os diferentes interpretantes ideológicos e subjetivos que deles resolvem se apropriar. 

tonal

\section{Referências Bibliográficas}

> ABBAGNANO, Nicola. Dicionário de filosofia. São Paulo: Mestre Jou, 1982.

$>$ BATTEUX, Charles. As belas-artes reduzidas a um mesmo princípio. São Paulo: Humanitas, Imprensa Oficial, 2009.

> CANDÉ, Roland de. A música, linguagem, estrutura e instrumentos. Lisboa: Ed.70, 1989.

> CASSIRER, Ernst. A filosofia do Iluminismo. Campinas: Editora da UNICAMP, 1997.

> CHRISTENSEN, Thomas. Rameau and musical thought in the enlightenment. Cambridge: Cambridge University Press, 1993.

$>$ CLARK, Suzannah e REHDING, Alexander (Org.). Music theory and natural order from the renaissance to the early twentieth century. Cambridge: Cambridge University Press, 2001.

> COLLINGW00D, Robin George. Idea de la natureleza. México: Fondo de Cultura Económica, 2006.

> CRAWFORD, Donald W. Estética da natureza e do meio ambiente. In: KIVY, Peter (org.). Estética. São Paulo: Paulus, 2008. p. 379-400.w

> DAHLHAUS, Carl. La idea de la música absoluta. Barcelona: Idea Books, 1999.

> DAHLHAUS, Carl. Studies in the origin of harmonic tonality. Oxford: Princeton University Press, 1990.

> DUDEQUE, Norton E. Harmonia tonal e o conceito de monotonalidade nos escritos de Arnold Schoenberg (1874 - 1951). Dissertação (Mestrado em Música) - Escola de Comunicações e Artes, Universidade de São Paulo, 1997.

$>$ DUDEQUE, Norton E. Music theory and analysis in the writings of Arnold Schoenberg. Aldershot: Ashgate, 2005.

> FUBINI, Enrico. La estética musical desde la antigüedade hasta el siglo XX. Madrid: Alianza Musical, 1994.

> FUBINI, Enrico. Los enciclopedistas y la música. Valência: Ed. Universitat de Valência, 2002.

> GOLLIN, Edward Henry. Representations of space and conceptions of distance in transformational music theories. PhD, Harvard University, 2000.

> GROUT, Donald J. e PALISCA, Claude V. História da música ocidental. Lisboa: Gradiva, 1994.

> HARNONCOURT, Nikolaus. 0 discurso dos sons. Rio de Janeiro: Jorge Zahar Ed., 1990.

> HARRISON, Daniel. Harmonic function in chromatic music: a renewed dualist theory and 

tonal

an account of its precedents. Chicago, University of Chicago Press, 1994.

$>$ HELMHOLTZ, Hermann von. On the sensations of tone as a physiological basis for the theory of music. New York: Dover Publications, 1954.

> HINDEMITH, Paul. Practica de la composición a dos voces. Buenos Aires: Ricordi Americana, 1962.

$>$ KAWANA, Karen Kazue. Natureza dividida: considerações sobre a ideia de natureza no século XVIII e sua influência na formação do pensamento romântico. Tese (Doutorado em História da Filosofia) - Instituto de Filosofia e Ciências Humanas, Universidade Estadual de Campinas, 2006.

> LEACH, Edmund. Natureza/cultura. In: ENCICLOPÉDIA Einaudi, v. 5. Porto: Imprensa Nacional - Casa da Moeda, 1985. p. 67-101.

> LENOBLE, Robert. Historia da ideia de natureza. Lisboa: Edições 70, 1990.

> LESTER, Joel. Compositional theory in the eighteenth century. Cambridge, Mass: Harvard University Press, 1996.

$>$ LESTER, Joel. Rameau and eighteenth-century harmonic theory. In: CHRISTENSEN, Thomas (Ed.). History of Western Music Theory. Cambridge: Cambridge University Press, 2006. p. 753-777.

> LÉVI-STRAUSS, Claude. Mitológicas: o cru e o cozido. São Paulo: Brasiliense, 1991.

> LOCKW00D, Lewis. Beethoven: a música e a vida. São Paulo: Códex, 2004.

$>$ LOVEJOY, Arthur 0. Essays in the history of ideas. Baltimore: The Johns Hopkins Press, 1965.

> LUCAS, Mônica Isabel. 0 ensaio sobre a imitação da natureza na música de Johann Adam Hiller (1754). Revista do Conservatório de Música da UFPel, n. 2, p. 27-46, Pelotas, 2009.

> MICHELI, Gianni. Natureza. In: ENCICLOPÉDIA Einaudi, v.18. Porto: Imprensa NacionalCasa da Moeda, 1990. p. 11-54.

> MOISÉS, Massaud. Fernando Pessoa: o espelho e a esfinge. São Paulo: Cultrix, 1988.

> MONTCOMERY David L. The myth of organicism: from bad science to great art. The Musical Quarterly, v. 76, n. 1, p. 17-66, 1992.

> MORENO, Jairo. Musical representations, subjects, and objects: the construction of musical thought in Zarlino, Descartes, Rameau, and Weber. Bloomington: Indiana University Press, 2004.

> NATTIEZ, Jean-Jacques. Harmonia. In: ENCICLOPÉdIA Einaudi v. 3. Porto: Imprensa Nacional - Casa da Moeda, 1984. p. 245-271.

> RAMEAU, Jean-Philippe. Démonstration du principe de l'harmonie servant de base à tout l'art musical théorique et pratique, 1750. Disponível em: 〈http://gallica2.bnf.fr〉. 

tonal

Acesso em: 12 fev. 2013.

> REYES, Pedro Redondo. La Harmónica de Claudio Ptolomeo. Tese de Doutorado Universidad de Murcia, 2002.

> ROUSSEAU, Jean-Jacques. Diccionario de música. Madrid: Ediciones Akal, 2007.

$>$ ROUSSEAU, Jean-Jacques. Do contrato social; Ensaio sobre a origem das línguas; Discurso sobre a origem e os fundamentos da desigualdade entre os homens; Discurso sobre as ciências e as artes. São Paulo, Abril Cultural, 1978.

$>$ ROUSSEAU, Jean-Jacques. Ensaio sobre a origem das línguas. Campinas: Ed. da Unicamp, 2008.

> ROWELL, Lewis. Introducción a la filosofia de la música. Barcelona: Editorial Gedisa, 2005.

> SALAZAR, Adolfo. La música en la sociedad europea. El siglo XIX (1). Madrid: Alianza Editorial, 1984.

> SCHENKER, Heinrich. Tratado de armonia. Madrid: Real Musical, 1990.

> SCHOPENHAUER, Arthur. 0 mundo como vontade e representação. São Paulo: Abril Cultural, 1974.

> SCHUBACK, Márcia Sá Cavalcante. A doutrina dos sons de Goethe a caminho da música nova de Webern. Rio de Janeiro: Ed. URFJ, 1999.

> SHIRLAW, Matthew. The theory of harmony: an inquiry into the natural principles of harmony, with an examination of the chief systems of harmony from Rameau to the present day. New York: Da Capo Press, 1969.

> TATARKIEWICZ, Wladyslaw. Historia de seis ideas: arte, belleza, forma, creatividad, mímesis, experiencia estética. Madrid: Ed.Tecnos, 2002.

> TOMÁS, Lia Vera. À procura da música sem sombra: Chabanon e a autonomia da música no século XVIII. São Paulo: Cultura Acadêmica, 2011.

> VIDEIRA, Mário. 0 Romantismo e o Belo Musical. São Paulo: Editora UNESP, 2006.

$>$ WASON, Robert W. Viennese harmonic theory from Albrechtsberger to Schenker and Schoenberg. Rochester, NY: University of Rochester Press, 1995.

> WILLIAMS, Raymond. Palavras-chave: um vocabulário de cultura e sociedade. São Paulo: Boitempo, 2007.

> ZILLES, Urbano. 0 mundo como natureza, sujeito e cultura. In: SOUZA, Draiton Gonzaga de, (Org.). Amor scientiae. Porto Alegre: EDIPUCRS, 2002. p. 665-680. 
Do lugar da natureza nas teorias dedicadas à arte da harmonia tonal

Sergio Paulo Ribeiro de Freitas, professor na Universidade do Estado de Santa Catarina (UDESC, Florianópolis) e membro dos grupos de pesquisa "Processos músico-instrumentais" (UDESC) e "Música Popular: história, produção e linguagem" (UNICAMP). É doutor em Música pela Universidade Estadual de Campinas e atua nas áreas de teoria, análise musical, contraponto, arranjo e harmonia tonal. sergio.freitas@udesc.br 